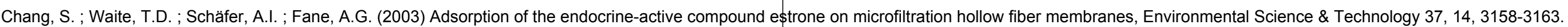
DOI: $10.1021 / \mathrm{es} 0261574$

\section{Adsorption of the Endocrine-active Compound Estrone on Microfiltration}

Hollow Fibre Membranes

\section{SHENG CHANG $^{1}$, T. DAVID WAITE ${ }^{1}$, ANDREA I. SCHÄFER ${ }^{1}$ and} ANTHONY G. FANE

${ }^{1}$ Centre for Water and Waste Technology, Civil and Environmental Engineering, The University of New South Wales, Sydney, NSW 2052, Australia

${ }^{2}$ UNESCO Center for Membrane Science and Technology, Chemical Engineering and Industrial Chemistry, The University of New South Wales, Sydney, NSW 2052, Australia

Environmental Science and Technology$$
\begin{aligned}
& \text { *Corresponding Author: } \\
& \text { Professor T. D. Waite }
\end{aligned}
$$

Email: D.Waite@unsw.edu.au

$$
\begin{aligned}
& \text { Email: D.Waite@ unsw.edu.au } \\
& \text { Tel: 61-2-9385 5060 Fax: 61-2-9385 } 6139
\end{aligned}
$$

\section{Abstract}

Results of studies reported here show that adsorption could result in considerable accumulation of hormones on hydrophobic hollow fibre membrane surfaces during filtration of trace-hormone containing feed solutions with a linear adsorption isotherm applicable over the majority of the estrone concentration range examined (2.6 to $154 \mathrm{ng} / \mathrm{L}$ ). Models based on both diffusion and surface reaction limitation were used to describe the kinetics of estrone adsorption to the membranes tested. Results indicate that the rate of adsorption of estrone to the hollow fibre membranes was limited principally by surface reaction rate rather than the rate of diffusive transport to membran wertion by pseudo-first order expressions. These results are of environmental significance, especially in drinking water applications, where contaminants such as natural and synthetic hormones may accumulate on the membranes and desorb during backwashing and membrane cleaning.

\section{Introduction} Endocrine disrupting and pharmaceutically active compounds which are excreted by humans and
enter the environment via effluent discharge from municipal sewage treatment plants (STPs) may have significant impacts on both biota exposed in the receiving environment and human health (1have significant impacts on both biota exposed in the receiving environment and human health (1-
3). Although field data suggest that modern activated sludge treatment processes could consistently 3). Although field data suggest that modern activated sludge treatment processes could consistently
remove most of the synthetic and natural hormones that enter the works (4), steroid estrogens such as estrone and estradiol still occur at significant concentrations in sewage effluent (4). These trace compounds, usually present in the range of 1 to $30 \mathrm{ng} / \mathrm{L}$, could exert significant effects on biota exposed in the receiving environment (5).

Since estrogens are hydrophobic organic compounds of low volatility, sorption could play an important role in determining the fate of these compounds during the wastewater treatment process. Johnson an treatment works. They suggested that the principle mechanisms for steroid estrogens removal in the activated sludge process would be sorption and biodegradation. In general, for more hydrophobic compounds such as the synthetic steroid $17 \alpha$-ethinylestradiol (EE2, $\log \mathrm{K}_{\text {ow }} \sim 4.1$ ) (6), sorption to sludge is likely to play a significant role in removal from solution, while for relatively weakly hydrophobic compounds such as estriol (E3), binding to the sludge would be expected to be a less dominant factor. Lai et al. (6) examined the binding of steroid estrogens to river sediment using well-controlled adsorption experiments with the solution spiked to a concentration of $0.1 \mathrm{mg} / \mathrm{mL}$. Their results showed that sorption could be a significant factor in reducing aqueous phase concentrations of these compounds.

Ultrafiltration and microfiltration membranes are being used increasingly widely in water treatment and reuse. Studies have shown that significant concentrations of macromolecules and other organics typical of natural waters and wastewaters could accumulate on the surfaces of such membranes due to adsorption. Mechanisms of protein-membrane interactions and the effects of these interactions on membrane filtration have been investigated by a number of researchers (7-9). Jones and O'Melia (10) recently studied the effects of $\mathrm{pH}$ and ionic strength on adsorption of BSA and humic acid to hydrophilic membranes and assessed the factors controlling the rate of adsorption by exam the Ther study showed that diffusion of these compounds to the membrane surface is fast compared to the reactions at the membrane surface. Electrostatic interactions were also found to be very important in determining the adsorption rate for the compounds examined.

This study, which is part of a larger project on investigation of hybrid membrane processes for trace hormones removal, was stimulated by preliminary findings that nearly complete removal of estrone from solution ocurred on passage of solutions containing low concentrations of this hormone through hydrophobic microfiltration hollow fibre membranes. Further studies showed that significant amounts of estrone could accumulate on hydr result of sorption processes. This phenomenon could exert an important impact on hormone removal and fate in a water treatment system where membranes are used as a process barrier, particularly if the adsorbed species were to be substantially desorbed during the periodic backwash operation and membrane cleaning. In this study, we focus on the characteristics of partitioning of estrone between membrane and solution, adsorption kinetics, and the possible desorption of absorbed estrone from the membranes on lowering feed concentration. The isotherm equilibrium relationship and the rate of adsorption for different initial concentrations have been assessed using batch adsorption experiments. Kinetic models for the adsorption and desorption processes have been developed from both experimental results and theoretical analysis.

\section{Experimental materials and methods}

Flask adsorption and dead-end filtration tests were carried out to assess the adsorption characteristics of estrone on hollow fibre membranes. The flask experiments were carried out in an 
incubator shaker (Bioline, Edwards Instrument Company, Australia) under conditions of $250 \mathrm{rpm}$ and $25{ }^{\circ} \mathrm{C}$. For dead-end filtration, a small bundle of hollow fibre membranes (membrane mas 0.04 gram, filtration area based on inner surface of the fibres: $0.00057 \mathrm{~m}^{2}$ ) was directly immersed in the test solutions and a peristaltic pump (Masterflex 7518-00, Cole-Parmer Instrument Company) was used to remove the permeate from the fibre lumen. The membrane tested was a hydrophobic polypropylene $0.2 \mu \mathrm{m}$ US FILTER hollow fibre membrane. The mean outer and inner diameters of by $50 \%$ alcohol before experiments.

$1 \mathrm{mM} \mathrm{NaHCO}_{3}$ and $20 \mathrm{mM} \mathrm{NaCl}$, which provided buffering to about $\mathrm{pH} 8$, surface water (TOCs: 5.7ppm, pH:7.0) and secondary effluent (TOCs $13.2 \mathrm{ppm}, \mathrm{pH} 7.2$ - 7.5) were used as the background solution. Test solutions were prepared by dissolving a certain amount of ${ }^{3} \mathrm{H}$-labelled estrone in the background solutions. The radio-labeled estrone (activity: $1.0 \mathrm{mci} / \mathrm{mL}$ ) was purchased from Sigma Aldrich, Australia. A Packard Instruments liquid scintillation counter which has a detection limit of approximately $0.1 \mathrm{ng} / \mathrm{L}$ for estrone was used for analysis of the radiomass balance according to change in concentration of estrone in the solution.

\section{Results and discussion}

Adsorption of estrone on hollow fibre membranes. Figure 1 shows the retention of estrone to the $0.2 \mu \mathrm{m}$ microfiltration membrane for dead-end filtration of estrone solutions of different concentration $(0.3$ to $843 \mathrm{ng} / \mathrm{L})$. In these experiments, a fresh membrane was used for each experiment and the retention of estrone to the membranes was assessed by measuring the concentration in the feed and permeate after 15 minutes of filtration with an imposed flux $2.9 \times 10^{-5}$ $\mathrm{m} / \mathrm{s}$. From this figure we can see that the estrone was almost completely removed on passage of the solutions through the membranes for all the concentrations tested. The adsorption of estrone to the tubing system, module potting head, and glass container used in the experiments was assessed by pumping estrone spiked solution $(35 \mathrm{ng} / \mathrm{L})$ through the system without membranes. Examination of concentration after two hours of recirculation indicated that the loss of estrone from the solution was negligible. Since the pore size of the membranes tested was several orders of magnitude larger than the estrone molecules (molecular weight $270 \mathrm{~g} / \mathrm{mol}$ ), this high degree of removal was presumably a result of adsorption rather than membrane sieving.

Figure 2 shows the concentrations of the permeate and feed on successive filtration of estrone solutions of different concentrations without changing the membranes during the filtration runs. In the experiments, estrone solutions which had concentrations of $668,155,68,35,13,566,159 \mathrm{ng} / \mathrm{L}$, were successively passed through the $0.2 \mu \mathrm{m}$ membranes. For each solution the filtration (with an imposed flux $2.9 \times 10^{-5} \mathrm{~m} / \mathrm{s}$ ) lasted for 30 minutes and the samples for the retention assessment for each solution were taken at 15 minutes after the filtration commenced. When the $668 \mathrm{ng} / \mathrm{L}$ solution first went through the fresh membranes, the concentration decreased from 668 to $37 \mathrm{ng} / \mathrm{L}$, indicating a $95 \%$ estrone removal but after the feed was changed to the $155 \mathrm{ng} / \mathrm{L}$ solution the permeate concentration increased from 37 to $84 \mathrm{ng} / \mathrm{L}$ representing a decrease in estrone retention from $95 \%$ to $46 \%$. During the successive filtrations of estrone solutions of 68,35 , and $13 \mathrm{ng} / \mathrm{L}$, the concentrations in the permeate became higher than those in the feed (Figure 2), suggesting that desorption occurred when these solutions passed through the membranes. Although the membranes ( retention was observed again on successive filtration of the higher concentration solutions $(566,159$ $\mathrm{ng} / \mathrm{L}$ ), indicating that the membranes were still not saturated for these high concentration solutions. The experimental results shown in Figure 2 suggest that the adsorption of estrone to the membrane surface is reversible. The positive retention to estrone is indicative of adsorption to the membrane surface, while the negative retention reflects desorption of estrone from the membrane surface.
Adsorption isotherm. The relationship between the quantity of solute adsorbed per unit mass of adsorbent and the solution concentration at the equilibrium state (i.e., the isotherm relationship) can be determined by flask adsorption experiments. In this study the flask experiments were carried out by placing a selected amount of hollow fibre membranes into a number of flasks which contained estrone solution of a specific initial concentration. The mixture of the membranes and the estrone solution was then shaken for 24 hours at constant temperature to ensure that adsorption equilibrium was reached.

The relationship between the equilibrium surface concentration $\left(\mathrm{C}_{\mathrm{se}}, \mathrm{ng} / \mathrm{g}\right)$ and solution concentration $(\mathrm{C}, \mathrm{ng} / \mathrm{L})$ for batch estrone adsorption experiments with different initial estrone concentrations $(250,130,60$ and $13 \mathrm{ng} / \mathrm{L})$ and membrane mass from 0.001 to 0.195 gram are shown in Figure 3. Data fitting showed that over the majority of the range of solution concentrations examined $(2.6$ to154.2 ng/L), the isotherm equilibrium can be described by the following linear model:

$C_{s e}=9.1 \cdot C_{c}$

The linear isotherm equilibrium relationship can be considered as the specific form of the Langmuir equation under a condition of $\mathrm{C}_{\mathrm{e}}<<\mathrm{C}_{\mathrm{smax}}$, where $\mathrm{C}_{\mathrm{smax}}$ is the surface saturation concentration or the surface concentration related to complete mono-layer coverage of adsorbate molecules over the adsorbent surface. The specific area of the hollow fibre membrane used can be roughly estimated to be $37.7 \mathrm{~m}^{2}$ per gram by assuming that the fibre membrane is a cylinder with a thickness of $0.15 \mathrm{~mm}$ and has homogeneous round pores of $0.2 \mu \mathrm{m}$ with an outer surface porosity of $40 \%$. Values of about $0.6-0.84 \mu \mathrm{g} / \mathrm{cm}^{2}$ for a monolayer of BSA molecules and 0.1 to $0.269 \mu \mathrm{g} / \mathrm{cm}^{2}$ for Suwannee (he estrone molecules on the membrane surface is comparable to such a level, the maximum surface concentration obtained in our experiments should be far below the saturation surface concentration.

Although the linear model (Eq 1) is applicable over the majority of the concentration range tested, it was found that the values predicted by the linear model deviated from the experimental data in the low concentration range. Figure 4 shows that the initial isotherm relationship gradually approaches the linear model through a proximate curve that is concave up when the equilibrium solution concentration increases from 2.8 to $13 \mathrm{ng} / \mathrm{L}$. The observed initial low affinity of the membrane adsorption of hydrophobic molecules from a polar solvent to a solid surface for which there is a moderate intermolecular attraction (11)

\section{Batch adsorption kinetics}

Effect of permeate flux flow. Batch adsorption experiments both under defined flux and without flux were carried out to assess the effect of permeate flow on adsorption kinetics. In the batch adsorption studies with flux, permeate was pumped out of the fibre lumen and then returned to the feed flasks. The feed flask was slightly shaken each time prior to sampling to ensure that the sample reflected the average concentration of the solution contained within. For studies without permeate flow, the batch adsorption was carried out in an incubator in which the flask containing $50 \mathrm{~mL}$ of estrone solution and 0.037 gram membranes was shaken at about $4 \mathrm{~Hz}$. Figure 5 shows the change in estrone concentration of the solutions with time for adsorption studies with and without flux. For in estrone concentration of the solutions with time for adsorption studies with and without flux. For
adsorption with shaking, the estrone concentration in the solution rapidly decreased from $30 \mathrm{ng} / \mathrm{L}$ to about $9 \mathrm{ng} / \mathrm{L}$ in the first one hour, indicating a 70\% decrease in the concentration of estrone. After two hours, the rate of adsorption obviously decreased. The residual solution phase concentration of 


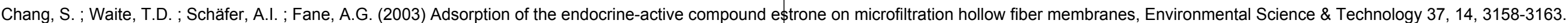
DOI: $10.1021 / \mathrm{es} 0261574$

estrone decreased by only $3 \%$ from 5 to 24 hours, suggesting an equilibrium state was reached in about 5 hours.

Comparing the kinetic behavior with and without flux, it can be seen that the rate of adsorption with a permeate flow rate of $1.3 \times 10^{-5} \mathrm{~m} / \mathrm{s}$ was slightly lower than the adsorption rates with both the higher permeate flow rate $\left(4.5 \times 10^{-5} \mathrm{~m} / \mathrm{s}\right)$ and flask shaking. The transportation of estrone to the hollow fibre membrane would be expected to involve bulk solution tansport, boundary laye film transport, internat p transport, intenal pore transpot, and adsorption. Since relavely low perneate flow is expected to favor estrone transport within the pores but is not as effective as shaking in assisting bulk transport, the lower adsorption rate with the permeate flow of $1.3 \times 10^{-5} \mathrm{~m} / \mathrm{s}$, at which $26.7 \mathrm{~mL}$ of solution passes through the membranes in one hour, could be attributed to bulk transport limitation. For adsorption with shaking, bulk transportation is usually not a limited factor. Given that nearly all of the adsorption capacity was provided by the internal pore surface, the higher adsorption rate with flask shaking suggests that the estrone molecules could be effectively transported to the adsorption site through boundary layer film transport and internal pore diffusion if they can be delivered to the mouths of the membrane pores.

Diffusion limited model. When considering adsorption as a process involving both solution-phase transport and surface processes, the rate of diffusion could limit the rate of adsorption if diffusion is much slower than processes at (or within) the solid surface $(10,12)$. Based on the one-dimensional diffusion equation and the Smoluchowski boundary condition (which is an assumption that the solute concentration in the interface immediately adjacent to membrane surface is zero), the following expression can be developed to describe the actual flux $\left(\mathrm{J}_{\mathrm{ac}}\right)$ to the membrane surface $(10,12)$

$J_{a c}=A \cdot\left[1-\frac{\Gamma(t)}{\Gamma_{e}}\right] \cdot J=C_{0} A \cdot\left[1-\frac{\Gamma(t)}{\Gamma_{e}}\right]\left(\frac{D}{\pi \cdot t}\right)^{1 / 2}$

J is the solute flux to the surface caused by diffusion $\left(\mathrm{ng} / \mathrm{m}^{2} / \mathrm{min}\right)$, D is the Stokes diffusion coefficient $\left(\mathrm{dm}^{2} / \mathrm{min}\right), \Gamma(\mathrm{t})$ and $\Gamma_{\mathrm{e}}$ are area based surface concentrations $\left(\mathrm{ng} / \mathrm{dm}^{2}\right)$ at time $\mathrm{t}$ and at equilibrium $(\mathrm{min})$, respectively, $\mathrm{C}_{0}$ is the initial concentration $(\mathrm{ng} / \mathrm{L})$, and $\mathrm{A}$ is a parameter between 0 and 1 . This parameter reflects the extent to which the adsorption is diffusion-controlled (10). When $\mathrm{A} \rightarrow 1$, the adsorption rate can be considered to be limited by diffusion. The term $\left[1-\Gamma(\mathrm{t}) / \Gamma_{\mathrm{e}}\right.$ ] represents the fraction of the total sites which remain available. Since the Smoluchowski condition assumes that no solutes delivered would remain in the liquid/surface interface we have: $\frac{d \Gamma(t)}{d t}=J_{a c}$

Combining equations 2 and 3, a modified diffusion model for adsorption of solutes onto solid surfaces can be developed as shown in equation $4(10,12)$ :

$\Gamma(t)=\Gamma_{e}\left\{1-\exp \left[\left(\frac{-2 A C_{0}}{\Gamma_{e}}\right)\left(\frac{D t}{\pi}\right)^{1 / 2}\right]\right\}$

Figure 6 shows the experimental data and kinetic behavior predicted by equation 4 for batch adsorption with shaking. In the simulation, A was used as a fitting parameter and determined to be in the range 0.0036 to 0.0047 for diffusion coefficients calculated by different correlations (Table1)

Although Figure 6 shows a good match between the experimental data and the kinetic behavior described by the diffusion limitation model, the small value of A (0.0036 to 0.0047$)$ implies that the adsorption rate was much lower than the diffusion rate; in other words, processes other than diffusion control the rate of estrone adsorption to the membrane surface under the experimental condition tested. This finding brings into question the fundamental assumption used in the development of the model that the concentration of the adsorbing species remains zero at the solid/liquid boundary (the so-called Smoluchowski condition)

Reversible adsorption model. An alternative approach to analysis of adsorption kinetics is to take account of the possible reversible nature of the adsorption process and to model accordingly. In this event, we may represent uptake of estrone on the membrane as follows:

$\mathrm{E}+\mathrm{M} \Leftrightarrow \mathrm{ME}$

where $\mathrm{E}$ represents estrone in solution, $\mathrm{M}$ represents the adsorption sites on the membrane surface, and $\mathrm{ME}$ represents the estrone accumulated on the membrane surface. The net rate of disappearance of $\mathrm{E}$ from the solution can be described by the second order kinetic expression:

$\frac{-d C_{t}}{d t}=k_{f} C_{t}[M]-k_{b} C_{s t}$

where $[M]$ is the number of the adsorption sites available at time $t$ and equal to $\mathrm{C}_{\mathrm{smax}}-\mathrm{C}_{\mathrm{st}}$. For $\mathrm{C}_{\mathrm{smax}} \gg \mathrm{C}_{\mathrm{st}}$, equation 6 can be simplified to a pseudo first-order expression as follows:

$\frac{-d C_{t}}{d t}=k_{f} C_{t} C_{s \max }-k_{b} C_{s t}=k_{f}^{\prime} C_{t}-k_{b} C_{s t}$

where $\mathrm{C}_{\mathrm{t}}(\mathrm{ng} / \mathrm{L})$ is the concentrations of estrone in solution at time $t$, and $\mathrm{k}_{\mathrm{f}}{ }^{\prime}\left(\min ^{-1}\right)$ and $\mathrm{k}_{\mathrm{b}}$ $(\mathrm{g} / \mathrm{L} / \mathrm{min})$ are the forward and back rate constants, respectively. To solve equation 7 , the following relations, based on the initial condition (equation 8), stoichiometry (equation 9), and equilibrium condition (equation 10), are used.

$t=0, \quad C_{t}=C_{0} \quad C_{s t}=0$

$C_{0}=C_{t}+\frac{m}{V} C_{s t}=C_{e}+\frac{m}{V} C_{s e}$

$\frac{C_{s e}}{C_{e}}=\frac{k_{f}{ }^{\prime}}{k_{b}}=K$

Combing equations $7-10, \mathrm{C}_{\mathrm{t}}$ can be solved as:

$C_{t}=\frac{C_{0}\left(1+\varphi K e^{-k_{b}(1+\varphi K) t / \varphi}\right)}{1+\varphi K}$

where $\varphi=m / V$ is the ratio of membrane mass to solution volume $(\mathrm{g} / \mathrm{L})$.

The equilibrium constant $\mathrm{K}(\mathrm{L} / \mathrm{g})$ and the back kinetic constant $\mathrm{k}_{\mathrm{b}}$ in the developed model (equation 11) were determined to be $4.47(\mathrm{~L} / \mathrm{g})$ and $0.0074(\mathrm{~g} / \mathrm{L} / \mathrm{min})$, respectively, by minimizing the sum of the squares of the difference between the experimental data collected from batch kinetic experiments with different initial concentration and the corresponding model solution; i.e

Minimize $\left[f\left(K, k_{b}\right)\right]=\sum_{i=1}^{m}\left[\left(C_{t}\right)_{\text {measured }}-\left(C_{t}\right)_{\text {calculation }}\right]^{2}$

The behaviour predicted by the pseudo first-order kinetic model is plotted as a solid line through the experimental data with different initial concentrations in Figure 7. The results show that this simple 


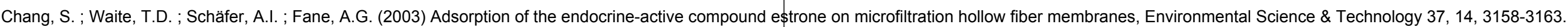
DOI: $10.1021 / \mathrm{es} 0261574$

first-order kinetic model fits the experimental data reasonably well for all four different initial concentrations. This suggests that the adsorption of estrone molecules to the membrane surface could be interpreted by formation of 1:1 surface complexes, the rate of which depends on the estrone solution concentration to a first-order. The model also predicts that the kinetic behavior is a function of membrane mass per unit volume of solution $(\mathrm{m} / \mathrm{V})$. The simulation results shown in Figure 8 indicate that the equilibrium concentration decreases with the increase in $m / V$ but, for higher values of $m / V$, longer times are required to reach the lower equilibrium concentrations.

One contradictory observation with regard to the pseudo first-order model for estrone adsorption to the membrane surface is that the equilibrium constant of 4.47 determined by the kinetic modeling is different from the value of 9.1 determined from the equilibrium adsorption experiments. Thi apparent discrepancy could result from the different partitioning behavior observed over different concentration ranges. The kinetic studies were undertaken at relatively low initial estrone concentrations where, as noted earlier, the tendency for estrone to adsorb to the membrane appears to be considerably lower than at higher estrone concentrations. Indeed, as shown in Figure 4, the trations predicted by the equilibrium constant derived in the equilitic kinetic studies are reasonably coincident with the actual partitioning data obtained in the
equilibrium studies in the lower initial estrone concentration range.

Desorption of estrone from the membranes. Experiments were carried out to assess the characteristics of desorption of estrone from the hollow fibre membranes. Initially, 0.02 gram hollow fibre membranes were placed in two flasks with $50 \mathrm{~mL}$ of estrone solution that had initia concentrations of 57 and $161 \mathrm{ng} / \mathrm{L}$, respectively. After 24 hour adsorption, the mass balance showed that the surface concentrations on the membrane bunches in the low and high concentration solutions were 105 and $290 \mathrm{ng} / \mathrm{g}$, respectively. The membrane bunches with adsorbed estrone were solution were (inture of the contaminated membrane and the buffer solutior $250 \mathrm{rpm})$. Sampling and analysis at specific time points showed that the estrone concentration in the solutions increased due to desorption of estrone from the contaminated membranes (Figure 9). A rapid rate of desorption was initially observed but decreased over time with an equilibrium state apparently established after about 180 minutes. About $14 \%$ of the adsorbed estrone was released for initial surface concentrations of both 105 and $290 \mathrm{ng} / \mathrm{g}$ when the equilibrium state was established. After attaining equilibrium, the solutions in both flasks were further diluted by $35 \mathrm{~mL}$ of the background electrolyte $(1 \mathrm{mM} \mathrm{NaHCO} / 20 \mathrm{mM} \mathrm{NaCl})$. The dilution resulted in a further desorption of estrone from the membranes (Figure 9). An increase in degree of destion of $4 \%$ for desopton of the two solutions was observed before a new equilibium was established after about 5 hours. These results indicate that the adsorption of estrone to the membranes is reversible and that desorption will naturally occur once the estrone concentration in the solution is lower than the equilibrium concentration.

The first order kinetic equation (equation 9) can also been used to describe desorption of estron from the membrane surface. For desorption, the mass balance and initial conditions can be written

$C_{0}+\frac{m}{V} C_{s 0}=C_{t}+\frac{m}{V} C_{s t}$

$t=0 \quad C_{t}=C_{0}$

$\mathrm{C}_{\mathrm{s} 0}$ is the initial surface concentration (ng/g). The following formula can then be developed for the desorption process:
$C_{t}=\frac{\left(C_{0}+\varphi C_{s 0}\right)-\varphi\left(C_{s 0}-K^{\prime} C_{0}\right) e^{-k_{b}^{\prime}(\varphi+K) t}}{1+\varphi K^{\prime}}$

For $\mathrm{C}_{0}=0$ :

$C_{t}=\frac{\varphi C_{s 0}\left(1-e^{-k_{b}^{\prime}\left(\varphi+K^{\prime}\right) t}\right)}{1+\varphi K^{\prime}}$

The equilibrium constant $\mathrm{K}^{\prime}$ and the back kinetic constant $\mathrm{k}_{\mathrm{b}}$ ' for desorption were determined to be $10(\mathrm{~L} / \mathrm{g})$ and $0.00167(\mathrm{~g} / \mathrm{L} / \mathrm{min})$, respectively, by the least squares method. The simulated desorption behavior is shown in Figure 9, indicating that the first order kinetic model can also describe the desorption process very well. The difference in kinetic constants between adsorption and desorption implies that the adsorption of estrone to the membrane surface may not be completely reversible. It appears that some estrone molecules are strongly (irreversibly) adsorbed and, as a result, will not readily desorb from the membranes and result in a higher equilibrium partitioning coefficient than may have otherwise been expected.

The results relating to batch adsorption of estrone to the membrane can be used to explain the phenomenon of retention of estrone by microfiltration membranes. Assuming that an equilibrium partitioning of estrone to the membrane can be built up on passage of the solution through the membrane, the concentration of estrone in the permeate will be a function of the amount of estrone accumulated on the membrane surface. When the surface concentration reaches the equilibrium value corresponding to the estrone concentration in the influent, the membrane will no longer adsorb estron from the influent and retention will cease. When the estrone concentation in the accumulated estrone will desorb from the men in the membrane and the retention become negative, resulting in that the concentration of estrone in the permeate becomes higher than that in the influent. These observations are confirmed by the initial filtration data in figure 2. In practice this would occur when the membranes are backwashed by permeate or other aqueous stream used to maximise desorption.

Figure 10 shows removal of estrone by adsorption to the membranes from different background solutions after 24 hours of adsorption (flasks shaken at $25^{\circ} \mathrm{C}$ and $250 \mathrm{rpm}$ ). It can be seen from and secondary effluent is slightly lower than from the buffer solution, suggesting that the extent of estrone adsorption may be reduced by competitive adsorption of other organics. The effect however is relatively minor indicating that, even in the presence of a variety of other adsorbing entities, a significant mass of estrone may still accumulate on the membrane material.

Acknowledgments

Funding for this research was provided by the Queensland Government and the Australian Research Council.

\section{Literature Cited}

(1) Ternes, T. A.; Stumpf, M.; Mueller, J.; Haberer, K.; Wilken, R. D.; Servos, M. Sci. Total Environ. 1999, 225, 81- 90.

(2) Hirsch, R.; Ternes, T. A.; Haberer, K.; Kratz, K. L. Sci. Total Environ. 1999, 225, 109 -118.

(3) Körner, W.; Bolz, U.; Süssmuth, W.; Hiller, G.; Schuller, W.; Hanf, V.; Hagenmaier, H. Chemosphere 2000, 40, 131-142.

(4) Johnson, A. C.: Sumpter, J. P. Environ. Sci. Technol. 2001, 35 (24), 4697 - 4703. 


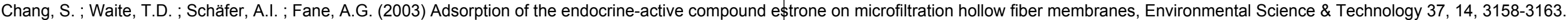
DOI: $10.1021 / \mathrm{es} 0261574$

(5) Purdom, C.E.; Hardiman, P. A.; Bye, V. J.; Eno, N. C. R.; Sumpter, J. P. Chem. Ecol. 1994, 8, $275-285$

(6) Lai, K. M.; Johnson, K. L.; Scrimshaw, M. D., Lester, J. N. Environ. Sci. Technol. 2000, 34 3890-3894.

(7) Matthiasson, E. J. Memb. Sci. 1983, 16, 23 - 36.

(8) Fane, A. G.; Fell, C. J. D.; Suki, A. J. Memb. Sci. 1983, 16, 195 - 210

(9) Palecek, S. P.; Zydney, A. L. Biotech Prog 1994, 10, $207-13$

(10) Jones, K. L.; O'Melia, C. R. J Memb. Sci. 2000, 165, 31- 46.

(11) Giles, C. H.; MacEwan, T. H.; Nakhwa, S. N.; Smith, D. J. Chem. Soc. 1960, 3973-3993.

(12) Bornzin, G. A.; Miller, I. F. J. Colloid Interface Sci. 1982, 86 (2), $539-558$

(13) Reid, R. C.; Prausnitz, J. M.; Poling, B. E. The Properties of Gases and Liquids, fourth ed., 1987, McGraw-Hill, New York
Table 1 A values obtained by calculating D with different correlations (13)

\begin{tabular}{|l|l|l|l|}
\hline Methods & Correlation & $\mathrm{D}\left(\mathrm{cm}^{2} / \mathrm{s}\right)$ & $\mathrm{A}$ \\
\hline Stokes-Einstein & $D_{A B}=\frac{R T}{6 \pi \eta_{B} \Psi r_{A}} \times 10^{7}$ & $3.73 \times 10^{-6}$ & 0.0046 \\
\hline Wilke-Chang & $D_{A B}=\frac{7.4 \times 10^{-8}\left(\Phi M_{B}\right)^{\frac{1}{2}} T}{\eta_{B} V_{A}^{0.6}}$ & $5.06 \times 10^{-6}$ & 0.0039 \\
\hline Tyn and Calus & $D_{A B}=8.93 \times 10^{-8} \frac{V_{B}^{0.267}}{V_{A}^{0.433}} \frac{T}{\eta_{B}}$ & $4.96 \times 10^{-6}$ & 0.0040 \\
\hline Nakamishi & $D_{A B}=\left[\frac{9.97 \times 10^{-8}}{\left(I_{A} V_{A}\right)^{\frac{1}{3}}}+\frac{2.40 \times 10^{-8} A_{B} S_{B} V_{B}}{I_{A} S_{A} V_{A}}\right] \frac{T}{\eta_{B}}$ & $5.81 \times 10^{-6}$ & 0.0036 \\
\hline $\begin{array}{l}\text { Hayduk and } \\
\text { Mink }\end{array}$ & $\begin{array}{l}D_{A B}=1.25 \times 10^{-8}\left(V_{A}^{-0.19}-0.292\right) T^{1.52} \eta_{B}^{\sigma} \\
\bar{\sigma}=9.58 / V_{A}-1.12\end{array}$ & $3.55 \times 10^{-6}$ & 0.0047 \\
\hline
\end{tabular}

$D_{A B}$ : diffusion coefficient of solute $A$ in solvent $B, \mathrm{~cm}^{2} / \mathrm{s} ; M_{B}$ : molecular weight of solvent $B, \mathrm{~g} / \mathrm{mol}$; $T$ : temperature, $\mathrm{K} ; V_{A}$ : molar volume of solute $A$ at its normal boiling temperature, $\mathrm{cm}^{3} / \mathrm{mol} ; V_{B}$ : molar volume of solute $A$ at its normal boiling temperature, $\mathrm{cm}^{3} / \mathrm{mol} ; \eta_{B}$ : viscosity of solvent $B, \mathrm{cp}$; $\Phi$ : association factor of solvent $B$ ( $\Phi=2.6$ for water), dimensionless; $I_{A}, S_{A}, S_{B}$, and $A_{B}$ : factors; $R$ : gas constant $831.4,(\mathrm{~N} \mathrm{~cm}) /(\mathrm{mol} \mathrm{K}) ; \Psi=6 \times 10^{23}$ 


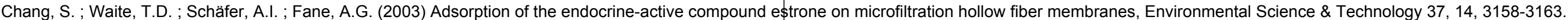
DOI: $10.1021 / \mathrm{es} 0261574$

\section{FIGURE CAPTIONS}

Figure 1

Figure 1 Estrone removal by $0.2 \mu \mathrm{m}$ hydrophobic hollow fibre membranes in dead end filtration of estrone solutions of different initial concentration.

Figure 2 Effect of successive filtration through the same membrane of estrone solutions of different feed concentrations (note that these feed concentrations refer to intial bulk values before actual contact with the "estrone loaded" membrane material)

Figure 3 Observed and predicted isotherm relationships for batch adsorption of estrone to the membrane over an estrone concentration range of 2.6 to $154.2 \mathrm{ng} / \mathrm{L}$.

Figure 4 Observed and predicted isotherm relationships for batch adsorption of estrone to the membrane over an estrone concentration range of 2.8 to $19 \mathrm{ng} / \mathrm{L}$.

Figure 5 Kinetics of estrone adsorption to the membranes with agitation by shaking and with recirculated permeate flow.

Figure 6 Observed and simulated kinetics of estrone adsorption to the membranes using a modified diffusion model for batch adsorption with agitation by shaking.

Figure 7 Observed and simulated kinetic behavior as predicted by a first order kinetic model for batch adsorption with agitation by shaking.

Figure 8 Simulated effect of membrane mass per unit volume $(\mathrm{m} / \mathrm{V})$ on kinetics of estrone adsorption to the membranes.

Figure 9 Observed and simulated desorption behavior for different concentrations of estrone initially adsorbed to the membranes.

Figure 10 Extent of estrone removal for different membrane masses in either bicarbonate buffer, surface water or secondary effluent.

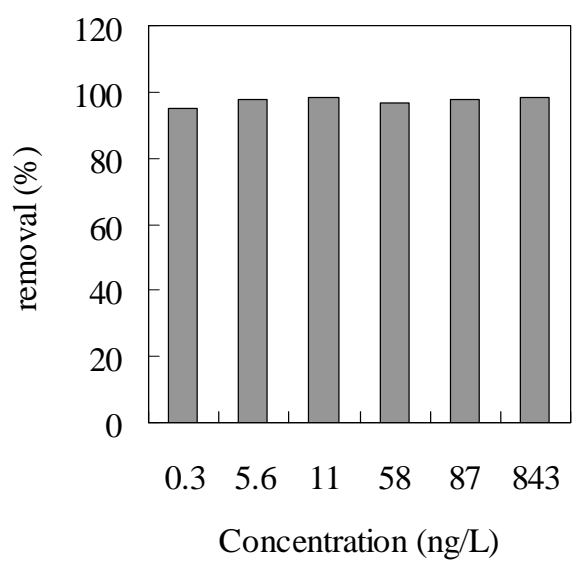

Figure 2

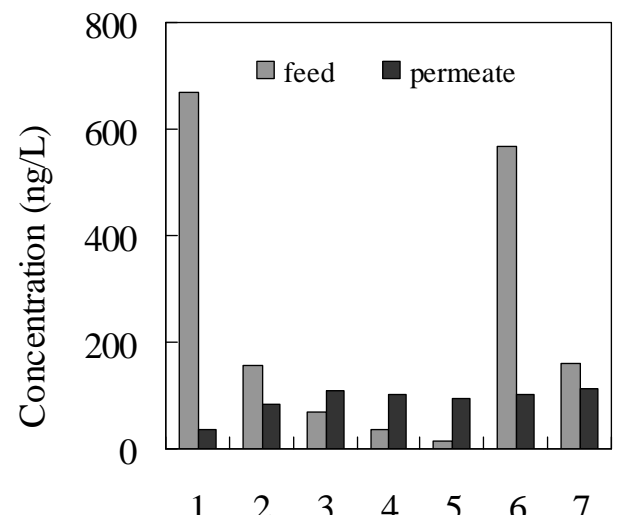

Order of filtration 


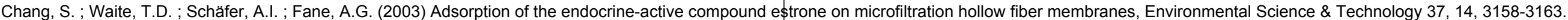
DOI: 10.1021/es0261574

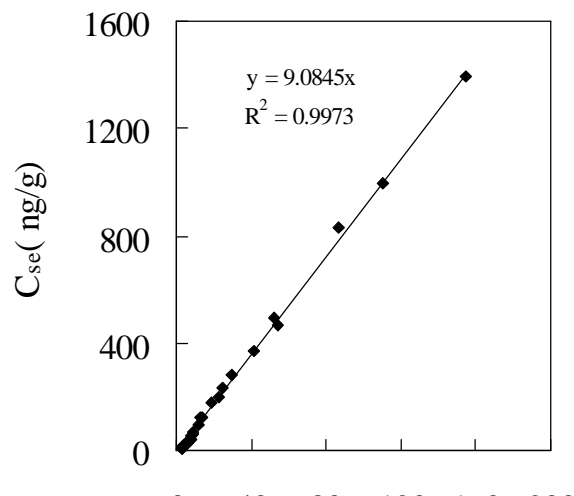

$\begin{array}{llllll}0 & 40 & 80 & 120 & 160 & 200\end{array}$

Ce (ng/L)

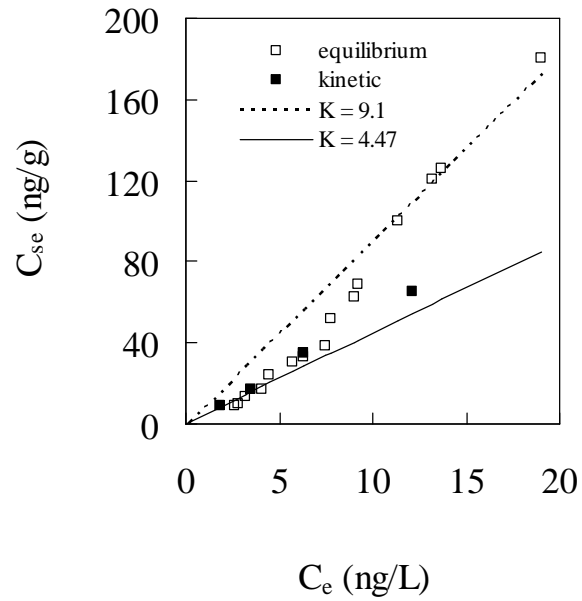

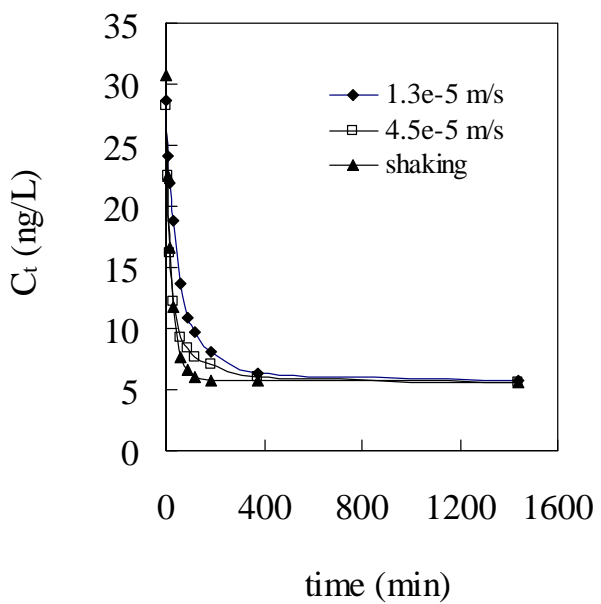

Figure 4

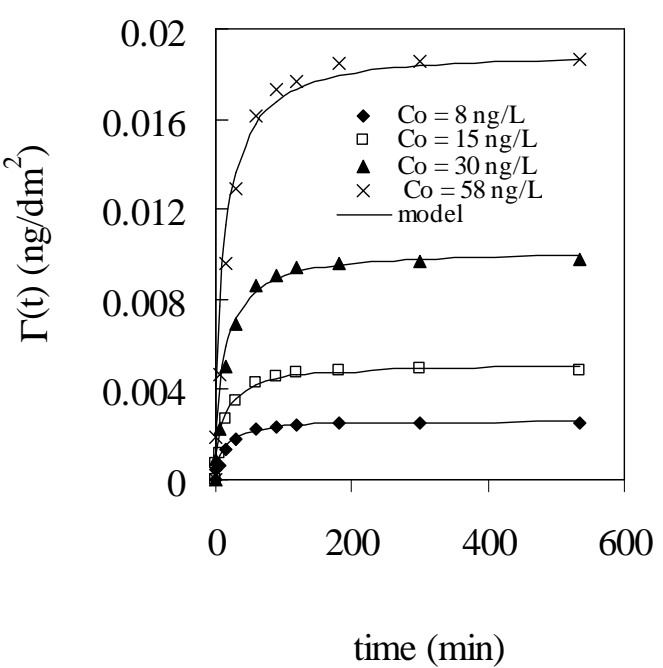

Figure 6

Figure 7 


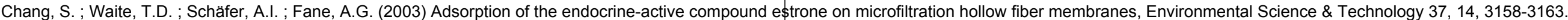
DOI: $10.1021 / \mathrm{es} 0261574$

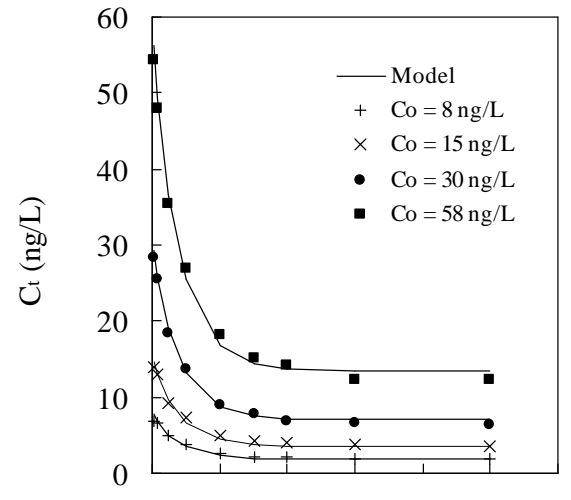

$\begin{array}{llllllll}0 & 60 & 120 & 180 & 240 & 300 & 360\end{array}$

time (min)

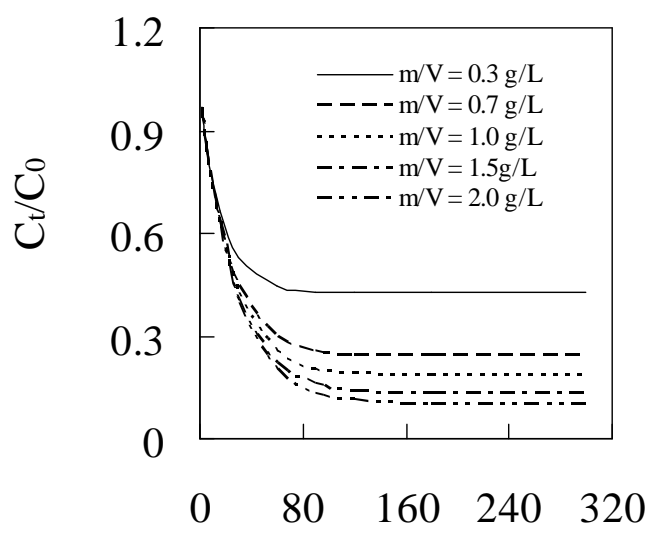

time (min)

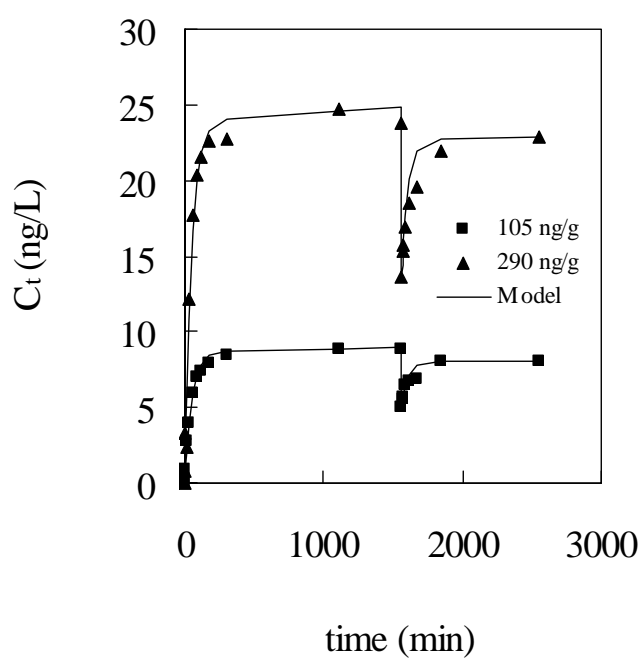

Figure 8

Brief

Endocrine-active compounds such as estrone may accumulate on hydrophobic hollow fibre membranes with the rate and extent of adsorption limited principally by reactions at the membrane surface.

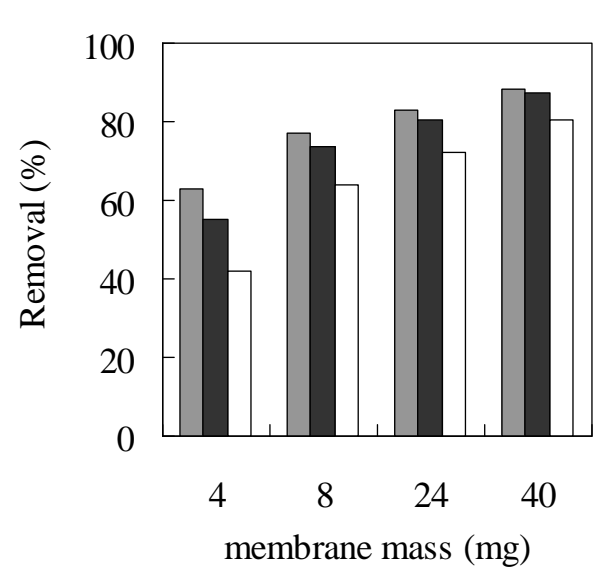

$\square$ buffer $\square$ surface water $\square$ secondary effluent

Figure 10

Figure 9 